\title{
Perfusion machines and hepatocellular carcinoma: a good match between a marginal organ and an advanced disease?
}

\author{
Davide Ghinolfi, Erion Rreka, Daniele Pezzati, Franco Filipponi, Paolo De Simone \\ Division of Hepatobiliary Surgery and Liver Transplantation, University of Pisa Medical School Hospital, Pisa, Tuscany, Italy \\ Contributions: (I) Conception and design: D Ghinolfi, D Pezzati, F Filipponi, P De Simone; (II) Administrative support: None; (III) Provision of study \\ materials or patients: None; (IV) Collection and assembly of data: D Ghinolfi, E Rreka, D Pezzati; (V) Data analysis and interpretation: D Ghinolfi; \\ (VI) Manuscript writing: All authors; (VII) Final approval of manuscript: All authors. \\ Correspondence to: Davide Ghinolfi, MD, PhD. Hepatobiliary Surgery and Liver Transplantation, University of Pisa Medical School Hospital, Via \\ Paradisa2, 56124, Pisa, Tuscany, Italy. Email: d.ghinolfi@ao-pisa.toscana.it.
}

\begin{abstract}
Hepatocellular carcinoma (HCC) accounts for $90 \%$ of primary liver cancers, is the second leading cause of cancer-related deaths and the leading cause of death in patients with cirrhosis. Liver transplantation (LT) represents the ideal treatment for selected patients as it removes both the tumor and the underlying cirrhotic liver with 5-year survival rates higher than $70 \%$. Unfortunately, due to tumor characteristics, patient co-morbidities or shortage of organs available for transplant, only $20 \%$ of patients can undergo curative treatment. Ex situ machine perfusion (MP) is a technology recently introduced that might potentially improve organ preservation, allow graft assessment and increase the pool of available organs. The purpose of this review is to provide an update on the current role of $e x$ situ liver MP in liver transplantation for HCC patients.
\end{abstract}

Keywords: Liver transplantation (LT); hepatocellular carcinoma (HCC); machine perfusion (MP); hypothermic; normothermic; marginal grafts

Received: 14 September 2017; Accepted: 27 September 2017; Published: 07 November 2017.

doi: $10.21037 /$ tgh.2017.10.01

View this article at: http://dx.doi.org/10.21037/tgh.2017.10.01

\section{Introduction}

Hepatocellular carcinoma (HCC) accounts for $90 \%$ of primary liver cancers (1), is the second leading cause of cancer-related deaths (2), and the leading cause of death in patients with end stage liver disease (ESLD) (3). Only in US 26,500 new cases are estimated to occur each year and approximately 782,000 are expected worldwide $(1,4)$. Unfortunately, the number of new cases diagnosed per year is almost equal than the number of HCC-related deaths, indicating that health care systems worldwide have no efficient answers to this ominous disease $(3,5,6)$.

The most frequent etiologies for cirrhosis in patients with HCC include chronic hepatitis due to hepatitis B (HBV) and $\mathrm{C}$ virus (HCV), and alcoholic liver disease. However, due to life-style changes, non-alcoholic fatty liver disease (NAFLD) is quickly rising as one of the leading etiologies for liver disease. In Western countries NASHrelated HCC incidence varies from $2.4 \%$ to $12.8 \%(7,8)$.

Treatment of HCC can be classified into curative, palliative or symptomatic. Curative treatment includes surgery, local tumor ablation and liver transplantation (LT). LT represents the standard treatment for patients with ESLD and HCC, with 5-year survival rate higher than 70\% (9). Unfortunately, due to tumor characteristics, patient comorbidities, or shortage of organs available for transplant only $20 \%$ of patients can undergo curative treatment $(10,11)$.

Although organ shortage is a well-known problem, pressure to expand the criteria to patients receiving liver transplants for HCC also exists. However, the anticipated decrease in patient survival due to expansion of selection criteria has fueled the debate about misusing a scarce resource (11). Recently, UNOS policy mandates a 6-month observation period prior to priority listing and institutes a 
cap of 34 MELD exception points for patients with HCC. Moreover, two additional changes to UNOS policy are under discussion (I) the use of locoregional treatment for small $(2-3 \mathrm{~cm})$ unifocal HCC before applying for exception points and; (II) to allow downstaging in selected patients with UNOS T3 lesions. Waiting list mortality and shortage of donor grafts should encourage to reserve LT to those to patients who may achieve significant benefit compared to non-transplant therapies (12).

\section{Extended criteria grafts: definition}

The necessity of expanding the donor pool spurred the transplant community to consider not only ideal donors but also extended criteria donors (ECD) as a possible source. Even if the concept of ideal donor is well defined (whole size liver graft from a donation after brain death (DBD), younger than 40 years of age, deceased for trauma, with a short intensive care unit (ICU) stay and no history of infectious diseases) $(13,14)$, the definition of ECD remains controversial. Elderly donors ( $>60$ years), macrovescicular steatosis $>30 \%$, donation after cardiac death (DCD), donors with malignancies or infections, hypernatremia, hemodynamic instability, prolonged cold ischemia time (CIT), split liver grafts, and living donor liver transplants (LDLT) are all included in this category (15-17). These grafts are potentially associated to a higher risk of medical and surgical complications, primary non-function (PNF), delayed graft function (DGF), malignancies and infectious diseases transmission, and a poorer prognosis after LT (18). For these reasons, their use is not universally implemented (17). Three categories of ECD are mainly used in western countries: old, steatotic, and DCDs.

\section{Age}

Ageing is responsible for well-known anatomical changes in the liver. Older hepatic parenchyma is characterized by brown atrophy, decreased weight and number of cells, progressive thickening of endothelial cell lining and increased endothelial cell fenestration. Liver blood flow is reduced with age and so are the synthetic and regenerative capacity leading to a progressively increased vulnerability to ischemia/reperfusion injury (IRI) $(13,19)$.

Moreover, the increased incidence of age-related risk factors in older donors, such as diabetes, hypertension, and dyslipidemia is responsible for a more severe hepatic steatosis and atherosclerotic disease (20-22) and may act in a synergistic way to further increase susceptibility to IRI (13).

Nevertheless, several studies have shown that use of grafts from well-selected populations of elderly donors can achieve results comparable to those using younger grafts (10) with similar incidence of vascular or biliary complications and only a slightly higher rate of re-LT due to early graft dysfunction $(17,23)$.

\section{Steatosis}

Steatosis is a very common chronic liver disease and it is estimated to occur in more than $65 \%$ of obese patients (24). Microvescicular steatosis is defined as accumulation of small fatty droplets not displacing the cell nucleus, but it does not determine a higher risk for graft loss after LT (25). On the opposite, macrovescicular steatosis, which is characterized by large droplets displacing the nucleus to the cell periphery, is related to a higher risk for graft failure and PNF $(25,26)$. Macrosteatosis is classified based on the proportion of hepatocytes affected in mild $(<30 \%)$, moderate (from $30 \%$ to $60 \%$ ), and severe $(>60 \%)(25-27)$. Under this circumstance, the liver might be more subjected to lipid peroxidation (28), a more accentuated proinflammatory response with release of mediators, such as tumor necrosis factor (TNF)- $\alpha$, and an increased neutrophil infiltration (29) thus heightening the sensitivity to I/R injury and increasing the risk of DGF and PNF. As a consequence, moderate macrosteatosis is still a relative contraindication to LT (25), while severe is mainly considered an absolute contraindication.

\section{$D C D$}

DCD refers to the recovery of organs from a donor who has experienced circulatory arrest after withdrawal of lifesustaining medical interventions or after an irreversible cardiac event. Despite their worse outcomes in terms of biliary complications, ischemic cholangiopathy and PNF when compared to DBD $(29,30)$, DCD utilization has steeply increased, accounting for $4.5 \%$ of all LT in the United States in 2008 compared with $0.5 \%$ in 1999 (31), while in UK about $28 \%$ of livers recovered from DCD donors are transplanted (32). Rapid surgical procurement technique, stringent thresholds of 30 minutes of total warm ischemia time (WIT) for organ acceptance, early initiation of recipient surgery in combination with selection of lowrisk recipients have yielded comparable graft survival at 1 and 3 years for DCD relative to DBD livers (33). 


\section{Machine perfusion (MP): pathophysiology and mechanisms of action}

MP technology was first introduced by Thomas Starzl, but was further developed in the last few years. The concept behind is to maintain the organ in a more physiological condition before implantation. This allows to reduce damages caused by cold storage (CS) as well as to assess organ function prior to transplantation. MP also opens an exciting prospect for organ repair and reconditioning prior to transplantation, which may expand the pool of donor organs beyond the currently accepted criteria (34).

The assumption that the main target of ex situ MP is to limit Ischemia/reperfusion injury (IRI), thus proving better graft for transplant, is an excessive simplification. Even if machine composition (a pump, a heater, an oxygenator) and function (to provide graft perfusion) is similar, several parameters may change during perfusion, thus creating multiple combinations of treatment and leading to completely different targets.

CS is still the gold standard for organ preservation but is associated with IRI. During the procurement, the graft is suddenly deprived of oxygen and cooled down with cold preservation solutions in order to slow metabolic processes (35). Yet, at $4{ }^{\circ} \mathrm{C}$ metabolism is not fully stopped, ATP is progressively depleted and mitochondrial function dysregulated (35). After reperfusion, the production of reactive oxygen species, cytokines secretion, neutrophil infiltration and the impaired hepatic microcirculation provoke inflammation, cell death, loss of functioning parenchyma and ultimately organ failure (36,37). Moreover, cholangiocytes are more susceptible to IRI and extended damage of the biliary epithelium is visible at the end of preservation of virtually all grafts $(38,39)$. Peribiliary vascular plexus and glands (containing the precursor's niche) are also damaged by microthrombi and necrosis, leading to impaired regeneration of the biliary epithelium (40). In the clinical setting, the manifestation of IRI can vary from immediate graft function with minimal damage to early allograft dysfunction (EAD), $\mathrm{PNF}$ and/or ischemic-type biliary lesions (ITBL).

Ex situ perfusion of donor livers, both in clinical or experimental activities, can be performed at four different temperature ranges: (I) hypothermia [(hypothermic machine perfusion (HMP)] $\left(0-12{ }^{\circ} \mathrm{C}\right)$; (II) midthermia [(midthermia machine perfusion (MMP)] (13-24 ${ }^{\circ} \mathrm{C}$ ); (III) sub-normothermia [(subnormothermic machine perfusion (SMP)] $\left(25-33^{\circ} \mathrm{C}\right)$; and (IV) normothermia [(normothermic machine perfusion (NMP)] $\left(35-38^{\circ} \mathrm{C}\right)(41)$. Studies using HMP are generally performed at temperatures ranging from 4 to $10^{\circ} \mathrm{C}$ in order to decrease metabolism and enzymatic reactions rate in mammalian cells as low as $20 \%$ or less $(42,43)$.

Timing during MP is another important issue as this technology can be applied at three particular time points: (I) immediately after organ procurement, before the organ is stored on ice for transportation; (II) before organ implantation; and (III) for the entire preservation period between procurement and implantation, thus (nearly) eliminating CS. When CS either before or after MP is less than $3 \mathrm{~h}$ the term preservation MP should be used (41).

Liver MP devices generally provide continuous inflow to the portal vein. The portal vein bed is an immense endothelial surface area accustomed to low pressures (normal physiological range, $5-10 \mathrm{mmHg}$ ). When perfusion is performed at subphysiological temperatures, even lower than normal pressure is required to prevent shear stress. The lowest possible pressure that may achieve adequate perfusion of the entire graft is influenced by the composition and temperature of the perfusate (44). The Zurich Group has described low-pressure $(2.5-3 \mathrm{mmHg})$ portal vein-only perfusion with University of Wisconsin gluconate solution at $10^{\circ} \mathrm{C}$ and has claimed complete graft perfusion under these conditions (45). Portal perfusion at pressures lower than this threshold is likely to be suboptimal (46). Especially under normothermic conditions, where oxygen requirements are high, the hepatic artery is additionally cannulated and pumped either in continuous or pulsatile fashion. Flow may be provided by a dedicated pump (47) or split between the portal vein and hepatic artery using a $\mathrm{Y}$ connector (44). A dedicated arterial pump offers the advantage of being able to provide more physiological pulsatile or continuous flow at higher pressures without risking inadvertent damage to the portal bed (44).

In addition to cannulating liver inflow, there are liver MP devices requiring cannulation of the hepatic outflow $(44,48)$. Although such a circuit might be considered more sterile due to lack of contact between the perfusate and ambient air, cannulating the inferior vena cava runs the risk of provoking hepatic congestion due to outflow resistance. As well, when the perfusion circuit is closed and all the effluent is recovered, it is very difficult to perform rapid cold perfusion to avoid graft loss in the case of technical malfunction during NMP/ subnormothermic machine perfusion (SMP) $(44,49)$.

\section{$H M P$}

The aim of HMP is to restore ATP levels and improve 
mitochondrial function prior to graft reperfusion (50,51). Improving mitochondrial function allows cells to better cope with the oxidative burst at reperfusion (44). In fact, aerobic respiration is reduced but not entirely ceased by hypothermia. Provision of high-energy metabolic substrate reduces cellular insults and also provides a dilutional and washout effect, thereby preventing the accumulation of toxic metabolites (52).

Experimental studies indicate that HMP helps improve hepatocellular preservation and graft survival when compared with cold storage $(53,54)$. However, the use of HMP may also be associated with significant Kupffer cell activation and endothelial cell injury $(55,56)$.

Dutkowski et al., comparing ATP concentration in CS and HMP, demonstrated that HMP livers provided a greater ATP content at 10 -h as compared to CS livers (51). While the mechanisms of this ATP loading remain obscure, perhaps the lower energy demand of a cooled liver and the continuous supply of oxygen may favor this positive ATP balance.

\section{NMP}

NMP aims to recreate the normal physiological milieu for the liver outside the body and avoid ischemia and hypothermia altogether by means of perfusing the graft with blood based solutions. Given that the liver is fully metabolically active, NMP also offers the best opportunity to assess and even improve graft viability prior to reperfusion in vivo $(52,57)$. NMP may lead to sustained viability, improved hemodynamics and attenuate ischemic injury in marginal livers (58). Nevertheless, the high concentration of pro-inflammatory cytokines in the perfusate during NMP after a prolonged period of CS promote concerns on the capacity of NMP to generate effective graft reconditioning and excellent cell metabolism (59)

Friend et al. were amongst the first to describe NMP and its benefits over standard CS as measured by preservation of alanine-aminotransferase (ALT) and enhanced Factor V production (60).

St Peter et al. also demonstrated that porcine DCD livers with 60 -min of WIT that underwent NMP faired significantly better than standard CS (61). Notably, ALT levels were markedly lower in NMP livers than CS controls after reperfusion, suggesting a much lower degree of hepatocyte cytolysis.

In experimental models, ex vivo NMP in DCD porcine livers at $38^{\circ} \mathrm{C}$ may also facilitate sustained oxygen extraction with normalized metabolism (62). ATP is likewise restored to pre-ischemia levels despite WIT of 1-h with NMP after cardiac arrest in Yorkshire pigs (63). During the warm ischemic phase in DCD grafts, ATP can rapidly be depleted (64). As such, this extracorporeal NMP system with porcine blood was able to reconstitute a more normal hepatic milieu after only 4-h of perfusion.

\section{$S M P$}

Although oxygen requirements are very low at $12{ }^{\circ} \mathrm{C}$ or less and no specific oxygen carrier is required, the adverse effects of hypothermia remain. MMP and SMP are performed to strike a balance between the detrimental effects of hypothermia and the high metabolic requirements present at physiological temperatures (44).

SMP has also been explored as a means to reconditioning marginal livers. Olschewski et al. suggested that perfusion at $21^{\circ} \mathrm{C}$ for 6 -h through the portal vein of Wistar rat livers after a 1-h WIT (DCD) was better than with temperatures of 4 or $12{ }^{\circ} \mathrm{C}(58)$. To reenact in vivo reperfusion, all livers were then perfused at $37^{\circ} \mathrm{C}$. Livers subjected to SMP at $21^{\circ} \mathrm{C}$ demonstrated reduced portal pressures, better bile production, and decreased markers of ischemia.

However, when studies have contrasted the use MMP or SMP with that of NMP, it was clear that the former remain unnatural and suboptimal forms of organ maintenance (44). Attempts to defat steatotic rat livers during MMP failed to demonstrate histological, hemodynamic, and metabolic improvements (65), unlike previous defatting studies performed using NMP $(66,67)$. Also, postreperfusion liver microarchitecture and bile production have been shown to be significantly improved when MP is performed at normothermic versus midthermic or sub-normothermic temperatures (45).

\section{MP devices}

Several groups have been exploring different methods of MP. Main differences in the setup of MP are determined by working temperature, provision of oxygen, the route and pressure of re-circulating preservation solution and if the volume of the perfusion is flow or pressure controlled.

\section{HMP}

The Group at Columbia University in New York was the first to report the application of HMP in clinical 
LT. They used non-transportable modified Medtronic Portable Bypass System (PBS) ${ }^{\circledR}$ (Minneapolis, USA) for portal vein and hepatic artery hypothermic perfusion. Based on this technology a transportable HMP (LifePort Liver Transporter $\left.{ }^{\circledR}\right)$, built on the same proven machine preservation technology platform as LifePort Kidney Transporter $^{\circledR}$, will be soon available.

After standard bench preparation, cannulation is performed as far as possible from potential anastomotic sites. The portal vein and the hepatic artery undergo continuous centrifugal HMP $(<3 \mathrm{mmHg})$ with perfusion solution. Flow rates are adjusted for graft weight and a total recirculating perfusate volume of $3 \mathrm{~L}$ is used. Hypothermia $\left(4-8{ }^{\circ} \mathrm{C}\right)$ is monitored with intraparenchymal temperature probes. Perfusion pressure is continuously monitored using a pressure transducer in the perfusion circuit. Portal vein and hepatic artery pressures are measured directly via indwelling angiocatheters attached to the perfusion device transducer. Flow rates are increased if the parenchymal temperature in either lobe rose above $7{ }^{\circ} \mathrm{C}$. The grafts do not require active cooling and hypothermia is provided with partial submersion in the basin of cold effluent. Active oxygenation is not utilized in this system (68).

\section{Hypothermic oxygenated perfusion (HOPE)}

The first device to be used was the ECOPS by Organ Assist. This is a single perfusion, non-transportable, portal-only HMP with actively oxygenated perfusion solution at $10^{\circ} \mathrm{C}$. Prior to implantation, the liver is connected to the ECOPS device (Organ Assist ${ }^{\circledR}, \mathrm{NL}$ ) and perfused through the portal vein only with a rotary pump that regulates perfusion pressure and (consequently) flow settings, with recirculated cooled $\left(10^{\circ} \mathrm{C}\right)$ and oxygenated $(40-60 \mathrm{kPa})$ perfusion solution through a membrane oxygenator. The Group in Zurich used to monitor perfusate $\mathrm{pO}_{2}, \mathrm{pCO}_{2}$, and $\mathrm{pH}$ during perfusion under a pressure adjusted below $3 \mathrm{mmHg}$, resulting in flow rates ranging from 100 to $150 \mathrm{~mL} / \mathrm{min}$ $(0.13 \mathrm{~mL} / \mathrm{min} / \mathrm{g}$ liver) (69).

\section{Dual bypothermic machine perfusion (D-HOPE)}

D-HOPE was performed by the Liver Assist ${ }^{\circledR}$ device (Organ Assist ${ }^{\circledR}, \mathrm{NL}$ ) which is a modified ECOPS device able to provide pressure-controlled dual (arterial and portal) perfusion of the liver using rotary pumps. In its clinical experience, the Group in Groeningen (NL) set arterial pressure at $25 \mathrm{mmHg}$ resulting in a pulsatile flow at 60 beats per min. A continuous portal flow is provided with a pressure of $5 \mathrm{mmHg}$. Pressure settings are sub-physiological to avoid shear stress-induced damage of the endothelium at low temperatures. Perfusate is maintained at $10^{\circ} \mathrm{C}$. The perfusion fluid is oxygenated by two hollow-fiber membrane oxygenators $(100 \%$ oxygen at $500 \mathrm{~mL} / \mathrm{min})$, resulting in a partial pressure of oxygen of at least $450 \mathrm{mmHg}$. Flow and resistance are assessed every $10 \mathrm{~min}$. Analysis of perfusate lactate and glucose is performed every 30 minutes from perfusate samples (70). Liver Assist ${ }^{\circledR}$ device is equipped with a heater and may vary perfusate temperature from 4 to $38^{\circ} \mathrm{C}$.

\section{NMP}

Two devices have been clinically used so far: the Metra ${ }^{\circledR}$ by $\mathrm{OrganOx}^{\circledR}(\mathrm{UK})$ and the Liver Assist ${ }^{\circledR}$ by Organ Assist ${ }^{\circledR}$ (NL). The first is a transportable device providing a continuous non-pulsatile arterial and portal flows powered by one rotary pump. Standard multiorgan retrieval is carried out and the liver was cooled in situ and transferred to the back-table for standard preparation. Portal vein, celiac trunk and bile duct are then cannulated before being reperfused on the machine. The device provides automated pumping, oxygen/air delivery, and heat exchange, in order to maintain the perfusate at normal temperature, within physiological ranges for $\mathrm{pO}_{2}, \mathrm{pCO}_{2}, \mathrm{pH}$, and at physiological pressures in the vascular inflows and outflow of the liver (hepatic artery pressure from 60 to $75 \mathrm{mmHg}$; IVC pressure (from 1 to 2 $\mathrm{mmHg}$ ). The portal pressure is not monitored (it is gravity regulated by the height of the portal venous reservoir continuously filled by the outflow perfusate), but portal flow is continuously measured. Bile duct is cannulated to monitor production. The device infuses (I) bile salt; (II) insulin; (III) heparin; (IV) prostacyclin, while glucose and amino acids infusion is regulated by 4-hourly manually inputted glucose levels. The device is primed with three units of packed red blood cells, and cross-matched to the donor, and one unit of colloid solution, with addition of calcium gluconate, heparin, cefuroxime and $30 \mathrm{~mL}$ of sodium bicarbonate. During priming, the perfusate should reach operating conditions: temperature $\left(37^{\circ} \mathrm{C}\right) ; \mathrm{pO}_{2}(12$ $\mathrm{kPa}) ; \mathrm{pCO}_{2}(5 \mathrm{kPa}) ; \mathrm{pH}(7.35)$ (48). The University of Toronto Group reported the perfusion of nine human DBD and three human DCD livers with OrganOx metra liver perfusion device by using human albumin based Steen solution instead of gelofusine (71).

Other groups performed NMP using the Liver Assist device (Organ Assist), which is a pressure-controlled 
Table 1 Clinical cases using hypothermic machine perfusion

\begin{tabular}{|c|c|c|c|c|c|c|c|}
\hline Author & No. of cases & Device & $\begin{array}{l}\text { Median donor age } \\
\text { (years) }\end{array}$ & $\mathrm{HCC}$ & Median MELD & EAD & Total biliary complications \\
\hline Guarrera et al. (68) & 20 & m-PBS & 39.4 & 5 [25] & 17.2 & $1[5]$ & $2[10]$ \\
\hline Dutkowski et al. (69) & 8 & ECOPS & 54 & $8[100]$ & 12 & NA & $0[0]$ \\
\hline De Carlis et al. (76) & 1 & LA & 47 & $1[100]$ & NA & $0[0]$ & $0[0]$ \\
\hline De Carlis et al. (77) & 7 & LA & 47.6 & $7[100]$ & 10.6 & $1[14]$ & $1[14]$ \\
\hline
\end{tabular}

Data are shown as number [\%]. HCC, hepatocarcinoma; MELD, model end stage liver disease; EAD, early allograft dysfunction; m-PBS, modified Medtronic Portable Bypass System ${ }^{\circledR}$; ECOPS, extracorporeal organ perfusion system; NA, not available; LA, Liver Assist .

perfusion machine providing pulsatile arterial and continuous non-pulsatile portal flow via two independent rotary pump circuits perfusate generally contains 3 units of $\mathrm{ABO}$ compatible blood plus variable quantity of succinylated gelatin. Several other components may be added depending on transplant group preferences (e.g., antibiotics, heparin, insulin, etc.). Operative conditions are generally set up at a temperature of $37^{\circ} \mathrm{C}$ and the target pressures in the hepatic artery (HA) and portal vein (PV) of 60 and $8 \mathrm{mmHg}$, respectively $(72,73)$.

Several other machines are under evaluation in clinical or experimental trials, such as OCS Liver ${ }^{\circledR}$ (TransMedics, Inc, Andover, MA, USA), or the PerLiver ${ }^{\circledR}$ (Aferetica, Mirandola, Italy).

\section{Clinical experiences}

\section{HMP}

The experiences in LT using HMP began in 2009 with the report by Guarrera et al. (68) and so far, 7 series have been published for a total of 102 cases (Table 1). The Group in New York reported the first clinical series of 20 adult prospective LT after HMP preservation compared to a matched group transplanted with CS livers (68). They used a dual (arterial and portal) perfusion system, flow rates were adjusted to graft weight, and temperature set between $4-8{ }^{\circ} \mathrm{C}$. No active oxygenation was used, even though level of $\mathrm{pO}_{2}$ remained stable at means of $137.2 \mathrm{mmHg}$. HMP was continued for a period ranging from 3 to 7 hours after a variable period of CS. Mean donor age was 39.4 \pm 2.5 . Mean recipients age was $55.4 \pm 6.2$, mean recipient MELD score was $17.2 \pm 7.4$. Post LT results showed no PNF, a similar incidence of vascular, biliary complications and graft and patients survival between the two groups, while incidence of EAD and hospital stay were better in the study group (5\% vs. $25 \%, \mathrm{P}=0.08$ and 10.9 vs. 15.3 days, $\mathrm{P}=0.008$ ).

The same group published a similar experience using 31 extended criteria livers already declined by the originating UNOS region (74), compared to ECD transplanted after CS in a matched control study design. Using the same device, liver grafts were perfused at $4-8{ }^{\circ} \mathrm{C}$ for a variable time ranging from 3 to 7 hours. Mean donor age and 57.5 \pm 8.0 . Recipient mean MELD score was 19.5 \pm 5.9. No differences were found in terms of EAD rates, 1-year patient and graft survival, while a reduced incidence of biliary complications (4 vs. $13, \mathrm{P}=0.016)$ and a shorter hospital stay $(13.64 \pm 10.9$ vs. $20.14 \pm 11.12, \mathrm{P}=0.001$ ) was showed in the HMP group.

The Zurich group developed a HOPE system for liver grafts. The first experience reported using this technique (69) described the series of 8 patients with ESLD receiving DCD grafts (Maastricht category III), with a median donor warm ischemia time of $38 \mathrm{~min}$. HOPE was performed for $1-2 \mathrm{~h}$ prior to reperfusion through the portal vein. The HOPE-perfusate was cooled at $10^{\circ} \mathrm{C}$ and oxygenated $\left(\mathrm{pO}_{2}=60 \mathrm{kPa}\right)$ using an ECOPS device $\left(\right.$ Organ Assist ${ }^{\circledR}$ ). Perfusion pressure was maintained below $3 \mathrm{mmHg}$. Grafts were transplant in eight recipients with a median MELD score of 12 . Post LT transaminases, ICU and hospital stays were comparable to eight matched DBD liver grafts. There was no intrahepatic biliary complication at a median follow up of 8.5 months.

Dutkowski et al. (75) analyzed then 25 DCD grafts transplanted at Zurich after HOPE, matched 1:2 with 
Table 2 Clinical cases using normothermic machine perfusion

\begin{tabular}{|c|c|c|c|c|c|c|c|}
\hline Author & No. of cases & Median donor age & Device & $\mathrm{HCC}$ & Median MELD & EAD & Total biliary complications \\
\hline Watson et al. (72) & 1 & 57 & LA & $0[0]$ & 14 & $0[0]$ & $0[0]$ \\
\hline Ravikumar et al. (48) & 20 & 58 & Ox & NA & 12 & $3[15]$ & $4[20]$ \\
\hline Bral et al. (49) & 9 & 56 & Ox & $2[22]$ & 13 & $5[55]$ & $0[0]$ \\
\hline Watson et al. (79) & 12 & 52 & LA & $3[25]$ & 17 & NA & $3[25]$ \\
\hline Mergental et al. (80) & 5 & 49 & Ox & $2[40]$ & 8 & $0[0]$ & $0[0]$ \\
\hline Angelico et al. (81) & 6 & 50 & Ox & $0[0]$ & 12 & NA & NA \\
\hline Ghinolfi et al. (59) & 2 & 53 & LA & $0[0]$ & 20 & $0[0]$ & $0[0]$ \\
\hline
\end{tabular}

Data are shown as number [\%]. HCC, hepatocarcinoma; MELD, model end stage liver disease; EAD, early allograft dysfunction; NA, not available; LA, Liver Assist ; Ox, OrganOx Metra ${ }^{\circledR}$

DCD liver grafts $(\mathrm{n}=50)$ from two European DCD LT programs (Rotterdam $n=40$ and Birmingham $n=10$ ) and with 50 conventional DBD LT. The device used was again the ECOPS device (Organ Assist ${ }^{\circledR}$ ) where perfusate was cooled at $10^{\circ} \mathrm{C}$, oxygenated $\left(\mathrm{pO}_{2}=80-100 \mathrm{kPa}\right)$ and grafts perfused through the portal vein for $1-2$ hours (median 118 minutes). Recipients median MELD score was 13 (range, 9-15). HOPE treatment of DCD livers significantly decreased graft injury compared with matched CS DCD livers regarding peak of ALT (1,239 vs. 2,065U/L, $\mathrm{P}=0.02)$, intrahepatic cholangiopathy $(0 \% v s .22 \%, \mathrm{P}=0.015)$, biliary complications ( $20 \%$ vs. $46 \%, \mathrm{P}=0.042)$, and improved 1 -year graft survival $(90 \%$ vs. $69 \%, \mathrm{P}=0.035)$. No graft failure due to intrahepatic cholangiopathy or PNF occurred in HOPE-treated livers, whereas $18 \%$ of unperfused DCD livers needed re-LT. In addition, HOPE-perfused DCD livers achieved similar results as control DBD livers in all investigated endpoints.

Based on the assumption that hypothermic oxygenated machine perfusion may restore hepatocellular energy status and reduce reperfusion injury in DCD livers, the group in Groningen developed the dual hypothermic oxygenated machine perfusion (DHOPE) system, in which liver grafts were reperfused both from the hepatic artery and the portal vein. They compared 10 consecutive DCD LT treated with end-ischemic DHOPE to 20 DCD LTs without DHOPE (70), matched for donor age, donor WIT, and recipient MELD score. Grafts were perfused for a median of 126 min [123-156]. Recipient median MELD score was 16 [16-22] but none has HCC. At 1 week after LT peak serum ALT and bilirubin levels were twofold lower in the DHOPE group than in the control group (median ALT: 966 vs. $1,858 \mathrm{UI} / \mathrm{L}$ respectively, $\mathrm{P}=0.006$; median bilirubin 1.0 vs. $2.6 \mathrm{mg} / \mathrm{dL}, \mathrm{P}=0.044)$. During $\mathrm{DHOPE}$, median hepatic adenosine 5 '-triphosphate (ATP) content increased 11 -fold, from 6 to $66 \mu \mathrm{mol}$ per g protein $(\mathrm{P}=0.005)$. There were no differences in terms of graft and patient survival or biliary complications, even though none of the 10 DHOPEpreserved livers required re-LT for ITBL, compared with 5 of 20 in the control group $(\mathrm{P}=0.140)$.

Finally, it is quite interesting the experience by the group in Milan applying end-ischemic hypothermic oxygenated dual perfusion in DCD grafts after a no touch period of 20 minutes as per Italian laws. Following a case report published in 2016 (76) they reported a series of 7 cases (77) of DCD grafts. In order to deal with the legally required no-touch period of 20 minutes, all donors were treated with normothermic regional perfusion (ECMO) after death declaration for a variable time range from 4 to 7 hours. Acceptance of the graft was based on the trend of serum transaminase and lactate during ECMO, macroscopic appearance at procurement, and liver biopsy result. In selected cases $(\mathrm{n}=4)$ ex situ HMP was performed using the Liver Assist ${ }^{\circledast}$ device for a mean of $182 \mathrm{~min}$. Recipients had a median MELD score of 10.6. Most notably, no cases of PNF were observed. Median post-LT ALT peak was 1,014 IU/L 
(range, 393-3,268 IU/L). Patient and graft survival were both $100 \%$ after a mean follow-up of 6.1 months (range, 3-9 months). No cases of ITBL occurred during the followup. Only 1 anastomotic stricture was noted, but completely resolved with endoscopic stenting.

\section{Normothermic liver perfusion}

Until July 2017, 11 manuscripts in form of original article or letter regarding human LT performed after ex vivo NMP have been reported in Literature, for a total of 68 procedures (Table 2). Indications to ex situ NMP, results and donor and recipient characteristics are quite heterogeneous. The first experiences, were performed as attempts to resuscitate very marginal grafts already discarded by most liver transplant centers $(72,78)$ and so far, only three randomized prospective series have been reported $(48,49,71)$.

The first human liver transplant using ex situ NMP was published by the group in Birmingham in 2016 (78). Graft was procured from a 29-years old, DCD donor. After care withdrawal, estimated WIT before complete cardiac arrest was 1 hour and 49 minutes. Because of the long WIT the graft was re-perfused on the LiverAssist ${ }^{\circledR}$ device at $37^{\circ} \mathrm{C}$. During perfusion lactate were quickly cleared and the graft started producing bile 30 minutes after re-perfusion. The liver was then transplanted on a 47 -year old recipient with alcoholic end stage liver disease complicated by encephalopathy, MELD score was 17. Ex situ NMP time was 416 minutes, total ex situ time was $13 \mathrm{~h}$ and 58 minutes. The recipient was discharged on POD\#10 and magnetic resonance cholangiopancreatography (MRCP) 6 months after LT was regular.

Almost simultaneously, the group in Cambridge (72) published a similar experience. A 57-year old DCD donor, with a period of 150 minutes between care withdrawal and circulatory arrest was re-perfused on the LiverAssist ${ }^{\circledR}$ device at $37^{\circ} \mathrm{C}$ after 5 hours of cold storage. During reperfusion, the quick drop of the lactate from 7.2 to $0.3 \mathrm{mmol} / \mathrm{L}$ within 74 minutes and the continuous production of bile induced to transplant the liver on a 58-years old female with alcoholic end stage liver disease complicated by encephalopathy and unresponsive ascites. The LT was uneventful and patient discharged on POD\#8. Cholangiography and liver function 6 months after LT were normal.

The first clinical trial was published by Ravikumar et al. (48) reporting $20 \mathrm{LT}$ performed at King's college Hospital and University Hospital in Birmingham. Grafts were perfused using the OrganOx Metra ${ }^{\circledR}$ device and compared to 40 matched control patients undergone transplantation of conventionally CS liver at the same centers. Primary end-point was 30 days graft survival. Over 20 patients, 16 were from DCD (Maastricht category 3) and 4 from DBD donors. Study group median donor age was 58.0 (range, 21-85) years, median recipient MELD score was 12 (range, 7-27), median DCD WIT before cross clamping was 21 minutes (range, 14-31 minutes). Median ex situ NMP time was 9.3 hours (range, 3.5-18.5 hours). Grafts were transplanted based on the maintenance of physiological $\mathrm{pH}$, bile production and stable vascular flows, and no liver was discarded during ex situ NMP. No cases of HCC were reported in this series. Thirty days graft survival was $100 \%$, no PNF and only 3 cases of EAD (15\%) were reported. No differences in terms of 30 days graft survival, PNF, EAD, ICU and hospital stay and 6 months patient survival was noted. A lower AST peak in the study group within 7 days after LT (417 vs. 902 UI, $\mathrm{P}=0.034$ ) was reported. In the first 6 months after LT 4 cases of anastomotic strictures were described in the study group.

Using the same technological device, two Canadian groups reported two prospective studies evaluating ten patients compared to an historical series $(49,71)$. The first to be published was the study by the Edmonton group which considered 4 DCD and 6 DBD grafts (49). One liver from a 60 years old DCD donor was procured and cannulated for NMP but promptly discarded because of an occult portal venous twist that retracted into the hilum, preventing perfusion. Parameters considered for accepting grafts during ex situ NMP were: variation in perfusate $\mathrm{pH}$, lactate concentration, perfusion vascular stability and continuous bile production. Median donor age was 56 years (range, 14-71 years), median ex situ NMP time was longer than in other experiences: 11.5 hours (range, 3.3-22.5 hours) and median recipient MELD score was 13 (range, 9-32). Study group was compared 1:3 with match control LT recipients receiving conventional CS grafts. No difference in terms of 30 days and 6 months graft survival, AST peak within 7 days, PNF, EAD, major complication and 6 months biliary complications was found. Nevertheless, ICU and hospital stay were longer ( 16 vs. $4, \mathrm{P}=0.004$ and 45 vs. $25, \mathrm{P}=0.01$ respectively) in the study group.

The group in Toronto (71), compared prospectively performed LT using grafts ex vivo perfused using OrganOx Metra ${ }^{\circledR}$ with an historical group of 30 patients based on step-wise matching for 30-day survival, donor age, recipient biological MELD score and donor type (DCD vs. DBD). 
Median recipient MELD score in the study group was 21 (range, 8-40). Median perfusion time was 480 minutes (range, 340-580 minutes). No technical problems occurred during machine perfusion or transport and all ex situ NMP preserved grafts functioned well after LT. Ex situ NMP vs. CS had lower AST and ALT values on POD\#1-3 without reaching significance. No difference in postoperative graft function between ex situ NMP and CS grafts was detected as measured by POD\# 7 INR (1.1, range, $1-1.56$ vs. 1.1, range, $1-1.3 ; \mathrm{P}=0.5)$ and $(1.5$, range, $1-7.7$ vs. $2.78 \mathrm{mg} / \mathrm{dL}$, range, $0.4-15 \mathrm{mg} / \mathrm{dL} ; \mathrm{P}=0.5)$. No difference was found in the duration of ICU stay ( $1 ; 0-8$ vs. $2 ; 0-23$ days; $\mathrm{P}=0.54)$ and post-LT hospital stay (median 11; range, 8-17 vs. 13 days; range, 7-89 days; $\mathrm{P}=0.5$ ). Major complications (Dindo-Clavien $\geqslant 3 \mathrm{~b}$ ) occurred in one patient in the ex situ NMP group (10\%) compared to seven patients $(23 \%)$ with CS $(\mathrm{P}=0.5)$. No graft loss or patient death was observed in either group.

Following these experiences Watson et al., (79) reported their first 12 cases performed using previously discarded grafts from 9 DCD and 3 DBD donors perfused using a Liver Assist ${ }^{\circledR}$ device. In these cases, performed over a 15 -month period, ex situ NMP began after a median cold storage period of 427 minutes (range, 222-877 minutes) and liver were perfused for a median of 284 minutes (range, 122-530 minutes). Totally the median time from circulatory arrest in the donor to reperfusion in the recipient was 12 hours 58 minutes (range, 9 hours 24 minutes to 26 hours 1 minute). Donor median age was 56 years (range, 24-67 years). Recipient median age was 57 years (range, 46-65 years) with a median MELD score of 17 (range, 10-26). One grafts experienced PNF and the recipients died despite urgent re-LT. Eleven patients are alive at a median follow up time of 12 months, even though three patients who received a DCD grafts showed cholangiopathy at MRCP.

A similar experience describing six discarded graft evaluated on ex situ NMP has been reported by the Birmingham group (80). Donors were 4 DCD and 2 DBD with a median age of 49 (range, 29-54) years and median CIT before ex situ NMP of 422 minutes (range, $387-474$ minutes). Device used was the Liver Assist ${ }^{\circledR}$ in 5 cases and OrganOx Metra ${ }^{\circledR}$ in 1. One graft was not used because did not meet viability criteria. Grafts were in fact evaluated within 3 hours of $e x$ vivo perfusion by (I) lactate level to be less than $2.5 \mathrm{mmol} / \mathrm{L}$; (II) bile production and a combination of at least one of these three: (i) perfusate
$\mathrm{pH}$ greater than 7.3; (ii) stable arterial flow of more than $150 \mathrm{~mL}$ and portal flow more than $500 \mathrm{~mL}$ per min; (iii) homogeneous graft perfusion with soft consistency of the parenchyma. Median ex situ NMP time was 332 minutes (range, 318-564 minutes) and the total preservation time of the transplanted liver was 798 minutes (range, 724-951 minutes). Median recipient age was 56 (range, 47-66) years, mean MELD score was 10 (range, 7-17). No surgical post-LT complications or cholangiopathy has been reported at 3 months after surgery. The same group reported a series of $6 \mathrm{LT}$ using grafts after ex situ NMP compared to 12 matched controls with CS grafts (81), reporting better intraoperative mean arterial pressure (MAP) at 90 minutes postreperfusion $(\mathrm{P}=0.029)$, achieved with a significantly less vasopressor requirement $(\mathrm{P}<0.05)$ and less transfusion of blood products $(\mathrm{P}=0.030)$ compared with CS group. Incidence of development of postreperfusion syndrome in the NMP $v s$. CS was not significant. None of the recipients had HCC.

Four more LT have been described by two Italian centers: Pisa $(\mathrm{n}=3)$ and Palermo $(\mathrm{n}=1)(59,73,82)$, all using DBD donors. The first group reported the use of ex situ NMP as salvage treatment for an 83-, 73- and 33-year-old donor, respectively, with insufficient perfusion at the time of procurement or following prolonged cardiocirculatory arrest. The group in Palermo (82) reported a single case of ex situ NMP performed on an 83-year-old graft discarded from other centers. In 2 cases $(50 \%)$, the graft was transplanted in a HCC recipient.

\section{Transplant for HCC with MP technology}

Based on current data from the international literature, a total of 50 patients (49\%) whose primary indications was HCC received a LT after ex situ HMP, and 13 (23\%) HCC patients after ex situ NMP.

Guarrera et al., in their first series with HMP (68), reported 5 patients $(25 \%)$ with HCC without PNF, with lower incidence of EAD and shorter hospital stay and with a similar incidence of vascular, biliary complications and graft and patient survival when compared to a control group.

In their second experience (74), they focused on orphan livers performing 31 transplants with 11 (35\%) HCC cases. No differences were found in terms of EAD rates, 1-year patient and graft survival, while a reduced incidence of biliary complications and a shorter hospital stay were shown when comparing the group to historical controls. Dutkowski et al. reported a series of 8 HCC recipients 
(6 histologically confirmed) and another series with 25 DCD grafts with 18 (72\%) HCC cases transplanted with HOPE at Zurich $(69,75)$. They found HOPE treatment of DCD livers significantly decreased graft injury regarding peak of alanine-aminotransferase (ALT), intrahepatic cholangiopathy, biliary complications, and improved 1-year graft survival, achieving similar results as control DBD livers in all investigated endpoints. De Carlis et al. reported a series of 7 HCC patients transplanted with DCDs with extended period of WIT ( $>20$ minutes) where they applied HMP after normothermic regional perfusion achieving $100 \%$ graft and patient survival with no incidence of ischemic cholangiopathy (77).

Two Canadian groups reported their experience with NMP. Bral et al. reported 2 out of $10(20 \%)$ patients with HCC in their series of transplants performed with NMP with results comparable to the control group (49). Selzner et al. reported 4 patients (40\%) with HCC with good outcomes (71). Watson et al. reported a series of 12 transplants performed with discarded liver; 3 of them (25\%) had HCC and all showed good outcomes (79). Mergental et al. reported a series of 6 discarded livers with 2 HCC; no surgical post-LT complications or cholangiopathy has been reported at 3 months after surgery (80). Our group previously reported a single case performed with marginal liver on a HCC recipient showing optimal result (73). Another single case with a marginal donor was reported by Di Francesco et al. with optimal results (82).

\section{Conclusions}

Clinical reports on ex situ machine perfusion are too scant to allow to derive clear indications on proper donor selection and recipient allocation. Ex situ MP is generally reserved for ECD grafts with concerns on post-LT performance, or with an estimated higher risk for post-LT complications, such as DCD grafts. At the moment, there is no consensus on which technique (HMP vs. NMP) is superior to another and in which context they should be used.

MP showed a potential to increase the donors' pool by recovering discarded or orphan livers, thus reducing the waitlist mortality, and MP-rescued grafts are generally allocated to low-MELD recipients, i.e., fitter to withstand initial graft dysfunction, which is quite rare in all of the reported experiences.

HCC patients have a lower possibility to be transplanted in a competitive allocation system due to their low MELD scores and are probably the first category that can benefit from extended criteria grafts preserved and recovered with MP technology. It is interesting to note that many series with MP have been performed using discarded grafts, thus showing an enormous potential to expand donors pool and to provide easier access to transplantation to HCC patients. The percentage of HCC patients receiving MP-rescued grafts is consistent with that reported in the literature for CS cases, and the higher rate observed in HMP seems more related to a higher use of DCD grafts than to the potential advantages of the technique. So far, use of ex situ MP technology is still too limited and further trials are necessary to test its safety efficacy. In the future, the anticipated increase in the number of grafts secondary to the systematic introduction of this technology, might play a relevant role in expanding indications for HCC.

\section{Acknowledgements}

None.

\section{Footnote}

Conflicts of Interest: The authors have no conflicts of interest to declare.

\section{References}

1. World Health Organization, International Agency for Research on Cancer. GLOBOCAN 2012 (Accessed July 27, 2014). Available online: http://globocan.iarc.fr/Pages/ fact_sheets_cancer.aspx

2. Ferlay J, Shin HR, Bray F, et al. Estimates of worldwide burden of cancer in 2008: GLOBOCAN 2008. Int J Cancer 2010;127:2893-917.

3. El-Serag HB. Hepatocellular Carcinoma. N Engl J Med 2011;365:1118-27.

4. American Cancer Society. Cancer facts \& figures 2014 [Internet]. Atlanta: American Cancer Society; 2014 [cited 2014 Dec 4]. Available online: http://www.cancer.org/ acs/groups/content/@research/documents/webcontent/ acspc-042151.pdf

5. Altekruse SF, McGlynn KA, Reichman ME. Hepatocellular carcinoma incidence, mortality, and survival trends in the United States from 1975 to 2005. J Clin Oncol 2009;27:1485-91.

6. White DL, Thritt AP, Kanwal F, et al. Incidence of Hepatocellular Carcinoma in All 50 United States, From 2000 Through 2012. Gastroenterology 2017;152:812-20.e1. 
7. Michelotti GA, Machado MV, Diehl AM. NAFLD, NASH and liver cancer. Nat Rev Gastroenterol Hepatol 2013;10:656-65.

8. White DL, Kanwal F, El-Serag HB. Association between nonalcoholic fatty liver disease and risk for hepatocellular cancer, based on systematic review. Clin Gastroenterol Hepatol 2012;10:1342-59.e2.

9. Mazzaferro V, Bhoori S, Sposito C, et al. Milan criteria in liver transplantation for hepatocellular carcinoma: an evidence-based analysis of 15 years of experience. Liver Transpl 2011;17:S44-57.

10. Lin S, Hoffmann K, Schemmer P. Treatment of hepatocellular carcinoma: a systematic review. Liver Cancer 2012;1:144-58.

11. Sapisochin G, Bruix J. Liver transplantation for hepatocellular carcinoma: outcomes and novel surgical approaches. Nat Rev Gastroenterol Hepatol 2017;14:203-17.

12. Rich NE, Parikh ND, Singal AG. Hepatocellular carcinoma and liver transplantation: changing patterns and practices. Curr Treat Options Gastroenterol 2017;15:296-304.

13. Feng S, Goodrich NP, Bragg-Gresham JL, et al. Characteristics associated with liver graft failure: the concept of a donor risk index. Am J Transplant 2006;6:783-90.

14. Pezzati D, Ghinolfi D, De Simone P, et al Strategies to optimize the use of marginal donors in liver transplantation. World J Hepatol 2015;7:2636-47.

15. Busuttil RW, Tanaka K. The utility of marginal donors in liver transplantation. Liver Transpl 2003;9:651-63.

16. Attia M, Silva MA, Mirza DF. The marginal liver donor-an update. Transpl Int 2008;21:713-24.

17. Ghinolfi D, Marti J, De Simone P, et al. Use of octogenarian donors for liver transplantation: a survival analysis. Am J Transplant 2014;14:2062-71.

18. Lai Q, Melandro F, Levi Sandri GB, et al. Use of elderly donors for liver transplantation: has the limit been reached? J Gastrointestin Liver Dis 2011;20:383-7.

19. Schmucker DL. Age-related changes in liver structure and function: Implications for disease? Exp Gerontol 2005;40:650-9.

20. Nardo B, Masetti M, Urbani L, et al. Liver transplantation from donors aged 80 years and over: pushing the limit. Am J Transplant 2004;4:1139-47.

21. Jiménez-Romero C, Clemares-Lama M, ManriqueMunicio A, et al. Long-term results using old liver grafts for transplantation: sexagenerian versus liver donors older than 70 years. World J Surg 2013;37:2211-21.

22. Grazi GL, Cescon M, Ravaioli M, et al. A revised consideration on the use of very aged donors for liver transplantation. Am J Transplant 2001;1:61-8.

23. Ghinolfi D, Lai Q, Pezzati D, et al. Use of elderly donors in liver transplantation: a paired-match analysis at a single center. Ann Surg 2017. [Epub ahead of print].

24. Fabbrini E, Sullivan S, Klein S. Obesity and nonalcoholic fatty liver disease: biochemical, metabolic, and clinical implications. Hepatology 2010;51:679-89.

25. Perez-Daga JA, Santoyo J, Suárez MA, et al. Influence of degree of hepatic steatosis on graft function and postoperative complications of liver transplantation. Transplant Proc 2006;38:2468-70.

26. Imber CJ, St Peter SD, Handa A, et al. Hepatic steatosis and its relationship to transplantation. Liver Transpl 2002;8:415-23.

27. de Graaf EL, Kench J, Dilworth P, et al. Grade of deceased donor liver macrovesicular steatosis impacts graft and recipient outcomes more than the Donor Risk Index. J Gastroenterol Hepatol 2012;27:540-6.

28. Berthiaume F, Barbe L, Mokuno Y, et al. Steatosis reversibly increases hepatocyte sensitivity to hypoxiareoxygenation injury. J Surg Res 2009;152:54-60.

29. Selzner M, Clavien PA. Fatty liver in liver transplantation and surgery. Semin Liver Dis 2001;21:105-13.

30. Jay CL, Lyuksemburg V, Ladner DP, et al. Ischemic cholangiopathy after controlled donation after cardiac death liver transplantation. Ann Surg 2011;253:259-64.

31. Thuluvath PJ, Guidinger MK, Fung JJ, et al. Liver transplantation in the United States, 1999-2008. Am J Transplant 2010;10:1003-19.

32. NHSBT. Organ Donation and Transplantation. 2014. [Last accessed on 2015 Sep 1]. pp. 1-163. Available online: http://www.organdonation.nhs.uk/statistics/transplant_ activity_report/

33. Mateo R, Cho Y, Singh G, et al. Risk factors for graft survival after liver transplantation from donation after cardiac death donors: an analysis of OPTN/UNOS data. Am J Transplant 2006; 6:791-6.

34. Sutherland AI. Oniscu GC Challenges and advances in optimizing liver allografts from donation after circulatory death donors. J Nat Sci Biol Med 2016;7:10-5.

35. Gilbo N, Catalano G, Salizzoni M, et al. Liver graft preconditioning, preservation and reconditioning. Dig Liver Dis 2016;48:1265-74.

36. Jaeschke H. Mechanisms of reperfusion injury after warm ischemia of the liver. J Hepatobiliary Pancreat Surg 
1998;5:402-8.

37. Fondevila C, Busuttil RW, Kupiec-Weglinski JW. Hepatic ischemia/reperfusion injury--a fresh look. Exp Mol Pathol 2003;74:86-93.

38. Brunner SM, Junger H, Ruemmele P, et al. Bile duct damage after cold storage of deceased donor livers predicts biliary complications after liver transplantation. J Hepatol 2013;58:1133-39.

39. Hansen T, Hollemann D, Pitton MB, et al. Histological examination and evaluation of donor bile ducts received during orthotopic liver transplantation--a morphological clue to ischemic-type biliary lesion? Virchows Arch 2012;461:41-8.

40. Hessheimer AJ, Cárdenas A, García-Valdecasas JC, et al. Can we prevent ischemic type biliary lesion in DCD liver transplantation? Liver Transpl 2016;22:1025-33.

41. Karangwa SA, Dutkowski P, Fontes P, et al. Machine perfusion of donor livers for transplantation: a proposal for standardized nomenclature and reporting guidelines. Am J Transplant 2016;16:2932-42.

42. Bruinsma BG, Berendsen TA, Izamis ML, et al. Determination and extension of the limits to static cold storage using subnormothermic machine perfusion. Int J Artif Organs 2013;36:775-80.

43. Dirkes MC, Post IC, Heger M, et al. A novel oxygenated machine perfusion system for preservation of the liver. Artif Organs 2013;37:719-24.

44. Hessheimer AJ, Fondevila C. Liver perfusion devices: how close are we to widespread application? Curr Opin Organ Transplant 2017;22:105-11.

45. Schlegel A, Kron P, De Oliveira ML, et al. Is single portal vein approach sufficient for hypothermic machine perfusion of DCD liver grafts? J Hepatol 2016;64:239-41.

46. 't Hart NA, der van Plaats A, Leuvenink HG, et al. Determination of an adequate perfusion pressure for continuous dual vessel hypothermic machine perfusion of the rat liver. Transpl Int 2007;20:343-52.

47. van der Plaats A, Maathuis MH, 'T Hart NA, et al. The Groningen hypothermic liver perfusion pump: functional evaluation of a new machine perfusion system. Ann Biomed Eng 2006;34:1924-34.

48. Ravikumar R, Jassem W, Mergental H, et al. Liver transplantation after ex vivo normothermic machine preservation: a phase 1 (first-in-man) clinical trial. Am J Transplant 2016;16:1779-87.

49. Bral M, Gala-Lopez B, Bigam D, et al. Preliminary singlecenter canadian experience of human normothermic ex vivo liver perfusion: results of a clinical trial. Am J
Transplant 2017;17:1071-80.

50. Lockett CJ, Fuller BJ, Busza AL, et al. Hypothermic perfusion preservation of liver: the role of phosphate in stimulating ATP synthesis studied by $31 \mathrm{P}$ NMR. Transpl Int 1995;8:440-5.

51. Dutkowski P, Odermatt B, Heinrich T, et al. Hypothermic oscillating liver perfusion stimulates ATP synthesis prior to transplantation. J Surg Res 1998;80:365-72.

52. Graham JA, Guarrera JV. Resuscitation of marginal liver allografts for transplantation with machine perfusion technology. J Hepatol 2014;61:418-31.

53. Lee CY, Jain S, Duncan HM, et al. Survival transplantation of preserved non-heart-beating donor rat livers: preservation by hypothermic machine perfusion. Transplantation 2003;76:1432-6.

54. de Rougemont O, Breitenstein S, Leskosek B, et al. Onehour hypothermic oxygenated perfusion (HOPE) protects nonviable liver allografts donated after cardiac death. Ann Surg 2009;250:674-83.

55. Monbaliu D, Heedfeld V, Liu Q, et al. Hypothermic machine perfusion of the liver: is it more complex than for the kidney? Transplant Proc 2011;43:3445-50.

56. Fondevila C, Hessheimer AJ, Maathuis MH, et al. Hypothermic oxygenated machine perfusion in porcine donation after circulatory determination of death liver transplant. Transplantation 2012;94:22-9.

57. Perk S, Izamis ML, Tolboom H, et al. A metabolic index of ischemic injury for perfusion-recovery of cadaveric rat livers. PLoS One 2011;6:e28518.

58. Olschewski P, Gass P, Ariyakhagorn V, et al. The influence of storage temperature during machine perfusion on preservation quality of marginal donor livers. Cryobiology 2010;60:337-43.

59. Ghinolfi D, Caponi L, Marselli L, et al. Anti-inflammatory signaling during ex vivo liver perfusion improves the preservation of pig liver grafts before transplantation. Liver Transpl 2017;23:707-8.

60. Friend PJ, Imber C, St Peter S, et al. Normothermic perfusion of the isolated liver. Transplant Proc 2001;33:3436-8.

61. St Peter SD, Imber CJ, Lopez I, et al. Extended preservation of non-heart-beating donor livers with normothermic machine perfusion. Br J Surg 2002;89:609-16.

62. Boehnert MU, Yeung JC, Bazerbachi F, et al. Normothermic acellular ex vivo liver perfusion reduces liver and bile duct injury of pig livers retrieved after cardiac death. Am J Transplant 2013;13:1441-9.

63. Xu H, Berendsen T, Kim K, et al. Excorporeal 
normothermic machine perfusion resuscitates pig DCD livers with extended warm ischemia. J Surg Res 2012;173:e83-8.

64. Kamiike W, Watanabe F, Hashimoto T, et al. Changes in cellular levels of ATP and its catabolites in ischemic rat liver. J Biochem 1982;91:1349-56.

65. Liu Q, Berendsen T, Izamis ML, et al. Perfusion defatting at subnormothermic temperatures in steatotic rat livers. Transplant Proc 2013;45:3209-13.

66. Nagrath D, Xu H, Tanimura Y, et al. Metabolic preconditioning of donor organs: defatting fatty livers by normothermic perfusion ex vivo. Metab Eng 2009;11:274-83.

67. Jamieson RW, Zilvetti M, Roy D, et al. Hepatic steatosis and normothermic perfusion-preliminary experiments in a porcine model. Transplantation 2011;92:289-95.

68. Guarrera JV, Henry SD, Samstein B, et al. Hypothermic machine preservation in human liver transplantation: the first clinical series. Am J Transplant 2010;10:372-81.

69. Dutkowski P, Schlegel A, de Oliveira M, et al. HOPE for human liver grafts obtained from donors after cardiac death. J Hepatol 2014;60:765-72.

70. van Rijn R, Karimian N, Matton APM, et al. Dual hypothermic oxygenated machine perfusion in liver transplants donated after circulatory death. Br J Surg 2017;104:907-17.

71. Selzner M, Goldaracena N, Echeverri J, et al. Normothermic ex vivo liver perfusion using steen solution as perfusate for human liver transplantation: First North American results. Liver Transpl 2016;22:1501-8.

72. Watson CJ, Kosmoliaptsis V, Randle LV, et al. Preimplant normothermic liver perfusion of a suboptimal liver donated after circulatory death. Am J Transplant 2016;16:353-7.

73. Pezzati D, Ghinolfi D, Balzano E, et al. Salvage of an octogenarian liver graft using normothermic perfusion: a case report. Transplant Proc 2017;49:726-8.

74. Guarrera JV, Henry SD, Samstein B, et al. Hypothermic

doi: $10.21037 /$ tgh.2017.10.01

Cite this article as: Ghinolfi D, Rreka E, Pezzati D, Filipponi F, De Simone P. Perfusion machines and hepatocellular carcinoma: a good match between a marginal organ and an advanced disease? Transl Gastroenterol Hepatol 2017;2:87. machine preservation facilitates successful transplantation of "orphan" extended criteria donor livers. Am J Transplant 2015;15:161-9.

75. Dutkowski P, Polak WG, Muiesan P, et al. First comparison of hypothermic oxygenated PErfusion versus static cold storage of human donation after cardiac death liver transplants: an international-matched case analysis. Ann Surg 2015;262:764-70; discussion 770-1.

76. De Carlis L, De Carlis R, Lauterio A, et al. Sequential use of normothermic regional perfusion and hypothermic machine perfusion in donation after cardiac death liver transplantation with extended warm ischemia time. Transplantation 2016;100:e101-2.

77. De Carlis R, Di Sandro S, Lauterio A, et al. Successful donation after cardiac death liver transplants with prolonged warm ischemia time using normothermic regional perfusion. Liver Transpl 2017;23:166-73.

78. Perera T, Mergental H, Stephenson B, et al. First human liver transplantation using a marginal allograft resuscitated by normothermicmachine perfusion. Liver Transpl 2016;22:120-4.

79. Watson CJE, Kosmoliaptsis V, Randle LV, et al. normothermic perfusion in the assessment and preservation of declined livers before transplantation: hyperoxia and vasoplegia-important lessons from the first 12 cases. Transplantation 2017;101:1084-98.

80. Mergental H, Perera MT, Laing RW, et al. Transplantation of declined liver allografts following normothermic ex situ evaluation. Am J Transplant 2016;16:3235-45.

81. Angelico R, Perera MT, Ravikumar R, et al. Normothermic machine perfusion of deceased donor liver grafts is associated with improved postreperfusion hemodynamics. Transplant Direct 2016;2:e97.

82. di Francesco F, Pagano D, Martucci G. Normothermic machine perfusion using an air/oxygen mixer for reconditioning a liver from a marginal brain death donor. Artif Organs 2017;41:E66-8. 